\title{
Utilizing Active Learning and Backwards Design to Articulate Learning Outcomes and Maximize Student Learning: An Integrating Model of Formative and Summative Assessment
}

\author{
Joseph Miglio \\ Berklee College of Music \\ This paper was presented at the 2019 International Summit of the \\ Music \& Entertainment Industry Educators Association
}

March 21-23, 2019

$\underline{\text { https://doi.org/10.25101/19.27 }}$

\section{Abstract}

Active learning is becoming a popular catch-phrase in education but it is much more than a fad or a bunch of "tips and tricks" on how to get students engaged in class. Active Learning is nothing less than a full-fledged paradigm shift in teaching and learning. This evidence-based approach is grounded in research about how the human brain learns and calls for significant changes to the way college courses are designed and to the roles of students and teachers in these courses.

This session will explore the context of the emerging shift in education away from the Transmission of Knowledge paradigm toward the Active Learning perspective, with a detailed focus on the cornerstone of Active Learning: Backwards Design. Backwards design uses carefully articulated course learning outcomes as the basis to create a course that includes the necessary opportunities for practice, assessment, and feedback that will foster real learning and student success. In a collaborative conversation, participants will discuss strategies to analyze the relationship between the "content" or topics of a course and the learning outcomes for that course, in an effort to delineate a process of developing meaningful and worthwhile course outcomes and unpacking these outcomes to uncover cognitive ability and implantation agility.

In an active learning course, the teacher's primary job is to design formative assessments that allow students to practice skills and make connections and then to use these "teachable moments" to offer feedback to steer students toward efficient and productive learning. Teachers, then, need to design authentic and relevant summative assessments where students can showcase what they have learned.
In our time together in this interactive session, we will:

- Investigate several formative $\rightarrow$ summative assessment schemes and models

- Discuss five Active Learning formative assessment techniques that can be adapted to any course and used in-class and/or out-of-class

- Consider the sorts of summative assessments that make the most sense in an Active Learning class.

- Provide a case analysis of a successful course that employed this model

- Offer resources and citations for additional information and instructional application

Keywords: active learning, backwards design, course design, student success, learning outcomes, formative assessment, summative assessment

Joseph (Joe) Miglio is an Associate Professor of Music Business/Management at Berklee College of Music, with areas of expertise including leadership and design thinking, strategic planning and business development, product development, and performance measurements. Miglio has presented at multiple national conferences on topics such as artist identity and income generation, personal brand marketing strategies, start up to scale up businesses models, competitive analysis and value propositions, trend analysis/ forecasting and innovative design. In 2012, Miglio received the Distinguished Faculty Award for the Professional Education Division at Berklee, based on his outstanding commitment to teaching, dedication to his students, and contributions to the curriculum. He was instrumental in the design and facilitation of the Professional/Career Development Seminar-its purpose to investigate and address common challenges associated with artist development and sustain- 
able business models that align with the core values of the artist and creating profit ability for that individual. This course is now required for all Berklee students. Joe has interviewed a variety of artist/musicians/business leaders including Janis Ian, John Oates, Victor Wooten, John Clayton, Ernie Isley, and Grace Kelly, looking at how their individual stories can find a common narrative in personal and professional advancement. Joe has a Doctorate in Education from National Louis University in Chicago and is the creator of the Reflexive Engagement Method, a model of inquiry based on self-knowledge construction and trans-personal understanding. His most recent work is based on the dual concept: "life is a conversation and life as a conversation."

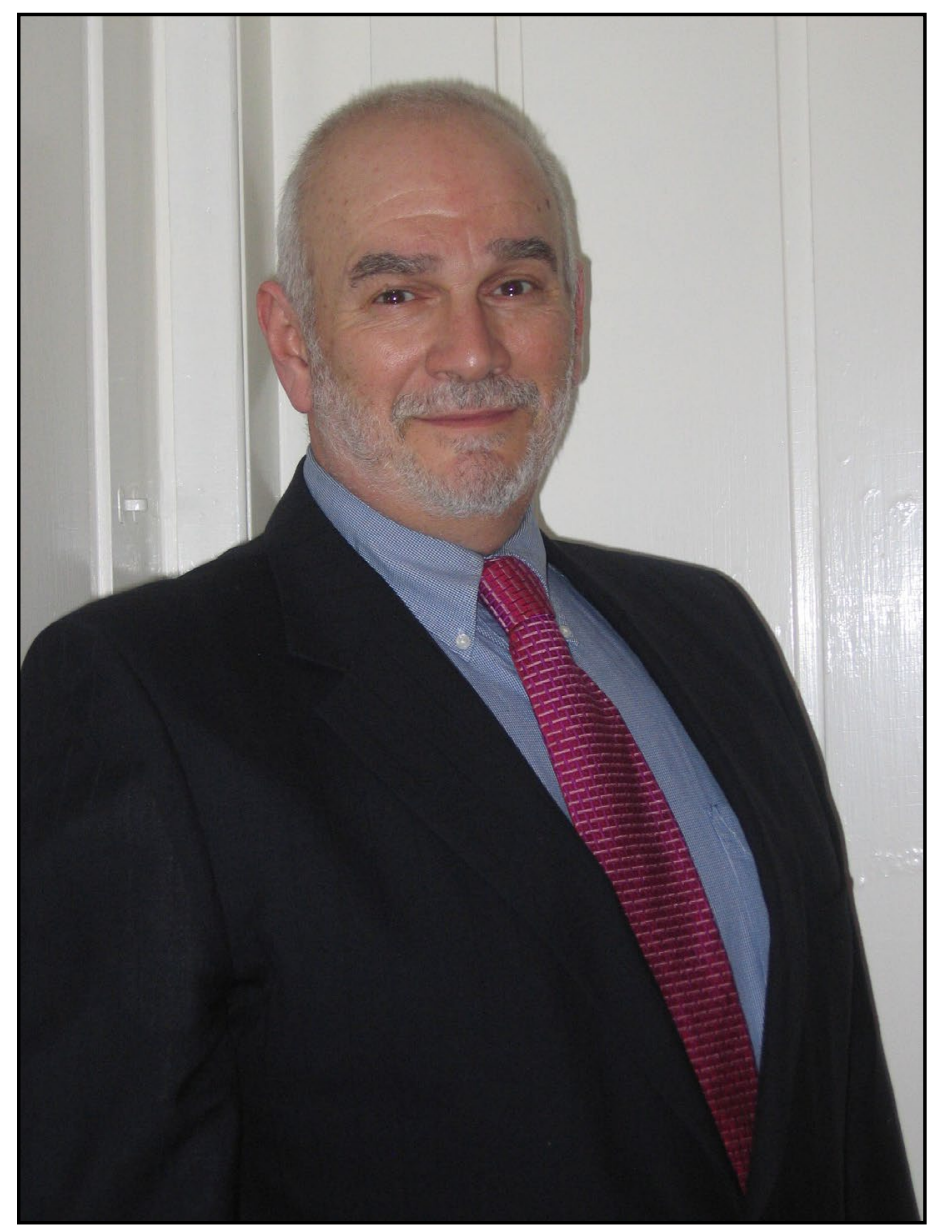




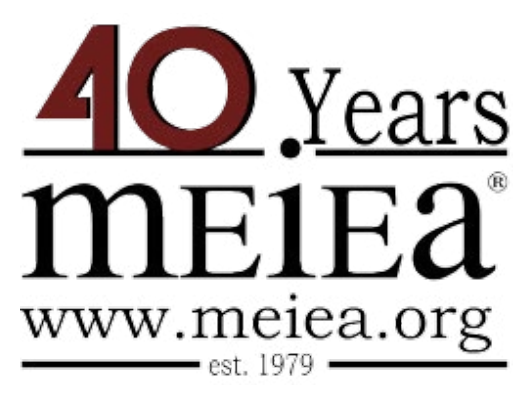

\section{PROCEEDINGS OF THE \\ 2019 INTERNATIONAL SUMMIT \\ OF THE \\ MUSIC \& ENTERTAINMENT \\ INDUSTRY EDUCATORS \\ ASSOCIATION}

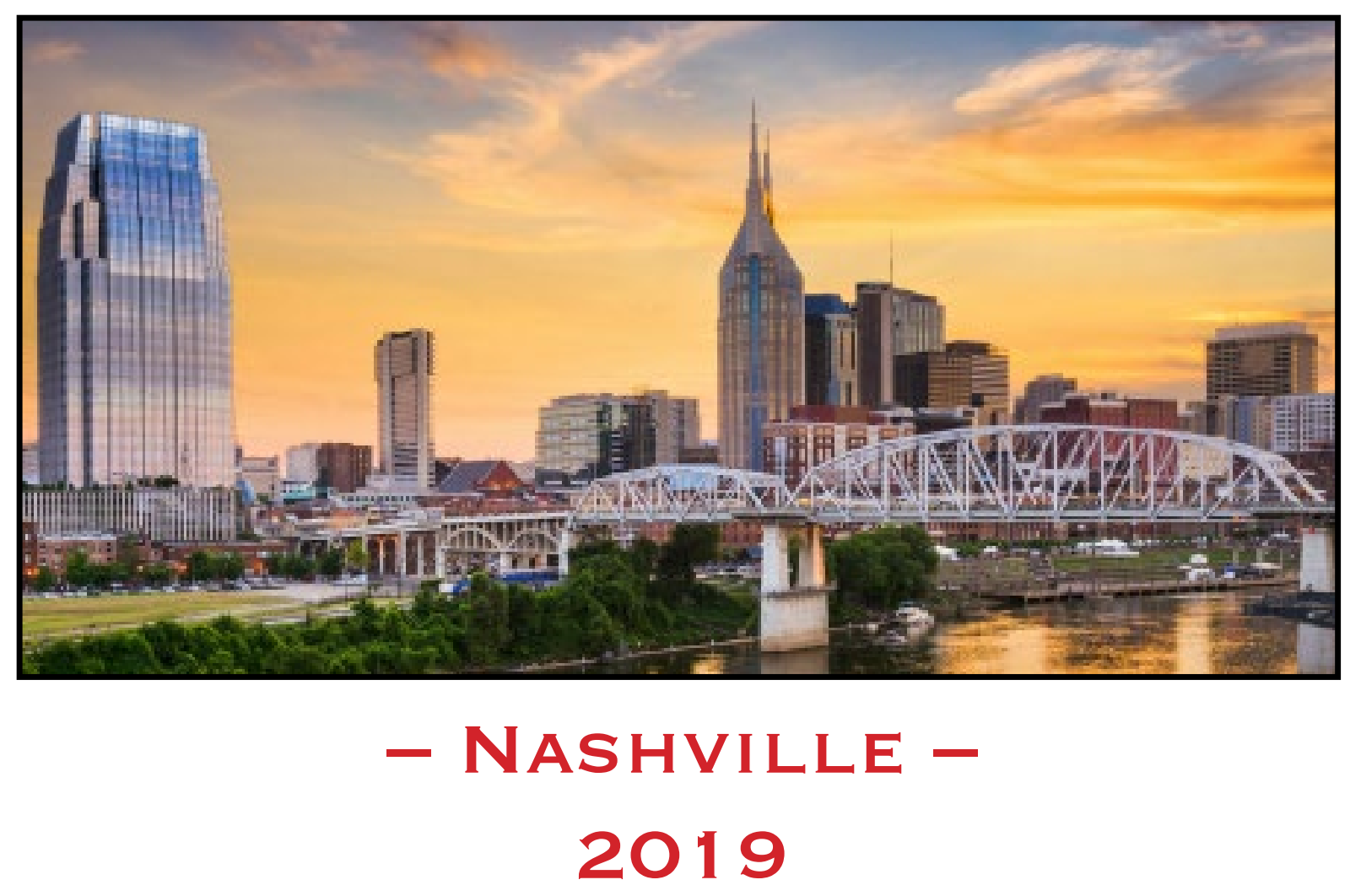

March 21 - 23, $2019 \cdot$ Belmont University - Nashville 